CLINICAL STUDY

\title{
Recognition of $5 \alpha$-reductase- 2 deficiency in an adult female 46XY DSD clinic
}

\author{
Marta Berra $^{1}$, Emma L Williams ${ }^{3}$, Barbara Muroni ${ }^{3}$, Sarah M Creighton ${ }^{2}$, John W Honour ${ }^{3}$, Gill Rumsby ${ }^{3}$ \\ and Gerard S Conway ${ }^{1}$ \\ Departments of ${ }^{1}$ Endocrinology, ${ }^{2}$ Gynaecology and ${ }^{3}$ Clinical Biochemistry, University College London Hospitals, 250 Euston Road, \\ London NW1 2BU, UK \\ (Correspondence should be addressed to G S Conway; Email: g.conway@ucl.ac.uk)
}

\begin{abstract}
Context: The late presentation of steroid 5 $\alpha$-reductase-2 (SRD5A2) deficiency in females is poorly characterised. The ratios of $5 \alpha / 5 \beta$-reduced metabolites of adrenal steroids in a urine steroid profile (USP) can give an indication of SRD5A2 deficiency, although the diagnostic cut-off for $5 \alpha / 5 \beta$ ratios are not clearly defined in genetically confirmed cases.

Objective: The aim of this study was to establish the frequency of SRD5A2 deficiency in an adult clinic for disorders of sexual development (DSD) focussing on 46XY partially virilised adult female subjects. We investigated the relationship between USP results and SRD5A2 genetic sequence and determined the cut-off for USP $5 \alpha / 5 \beta$-reduced steroid ratios compared with gene sequencing for the identification of SRD5A2 deficiency.

Methods: USP and SRD5A2 genetic analyses were performed in 23 adult females, aged 19-57 years, with 46XY DSD and in four males with confirmed SRD5A2 deficiency. 5 $\alpha$-Reductase activity was assessed using the USP ratio of androsterone to aetiocholanolone (A/Ae), $5 \alpha$-tetrahydrocortisol $(5 \alpha-\mathrm{THF}) /$ tetrahydrocortisol (THF) and $5 \alpha$-tetrahydrocorticosterone to tetrahydrocorticosterone ( $5 \alpha-\mathrm{THB} / \mathrm{THB})$.

Results: The SRD5A2 gene mutations were found in 10/23 (43\%) females and in all four males. Totally, four novel mutations were identified. All mutation-positive subjects had A/Ae and $5 \alpha-\mathrm{THB} / \mathrm{THB}$ ratios below the lower limit of normal (100\% sensitivity) while the sensitivity of $5 \alpha$-THF/THF ratio was $90 \%$. Conclusion: SRD5A2 deficiency is more prevalent than expected in the adult female 46XY DSD population. The clinical spectrum of this disorder may extend to a more female phenotype than previously considered to include individuals with little or no virilisation.
\end{abstract}

European Journal of Endocrinology 164 1019-1025

\section{Introduction}

The diagnostic pathway for disorders of sexual development (DSD) is almost entirely based on paediatric experience (1). There is little guidance for making an accurate diagnosis in adults with a female phenotype who might present with amenorrhoea or who have had a previous diagnostic workup that cannot be verified. For instance, the phenotype of women with a $46 \mathrm{XY}$ genotype, absent uterus and a degree of virilisation may have several genetic aetiologies including mutations in genes encoding the androgen receptor (AR), 17ß-hydroxysteroid dehydrogenase-3 (HSD17B3), $5 \alpha$-reductase-2 (SRD5A2) and steroidogenic factor (NR5A1). In practice, this group often comes under a poorly defined clinically based label of partial androgen insensitivity syndrome (PAIS) (2).

After gonadectomy, it is particularly difficult to make a biochemical diagnosis in adults when the original endocrine data are often not available (3), although those with SRD5A2 deficiency characteristically show decreased ratios of $5 \alpha$ - to $5 \beta$-reduced steroid metabolites. The ratios used are androsterone/aetiocholanolone (A/Ae), reflecting metabolism mainly of the C19 steroid dehydroepiandrosterone sulphate; 5 $\alpha$-tetrahydrocortisol ( $5 \alpha$-THF)/tetrahydrocortisol (THF), derived from cortisol; and $5 \alpha$-tetrahydrocorticosterone ( $5 \alpha$-THB)/tetrahydrocorticosterone (THB) from corticosterone (4). The SRD5A2 gene is found on chromosome $2 \mathrm{p} 23$ and is expressed during foetal life. SRD5A2 deficiency is inherited as an autosomal recessive trait with at least 68 mutations described (http://www. hgmd.cf.ac.uk, accessed December 2010).

We hypothesised that SRD5A2 deficiency may be the underlying diagnosis in some women with 46XY DSD. Most of the literature on this disease, however, refers to cohorts of children with ambiguous genitalia with an emphasis on the male end of the phenotypic spectrum (5). Relatively little is known about those in an older age group that present as 46XY females with absent uterus 
and virilisation at puberty (6-8). We used both biochemical and genetic methods to document the prevalence of SRD5A2 deficiency in partially virilised $46 \mathrm{XY}$ DSD living as women. We also aimed to define the most informative cut point for $5 \alpha / 5 \beta$-reduced steroid ratios in adults that could identify subjects who potentially harbour SRD5A2 gene mutations.

\section{Subjects and methods}

\section{Subjects}

In total, 23 females attending DSD clinics at the University College London Hospitals were recruited with the clinical characteristics of 46XY DSD presenting as phenotypic female with an absent uterus and partial virilisation. The degree of virilisation varied from those with ambiguous genitalia at birth $(n=11$ including three considered to have micropenis), those with normal early appearances and virilisation at or after puberty $(n=11)$ and one female with minimal virilisation whose sister clearly virilised at puberty. Women with complete androgen insensitivity syndrome (CAIS), defined clinically as no signs of virilisation and no family history of unusual virilisation, were not included. A comparison group of four males with the classical biochemical presentation of SRD5A2 deficiency was included. This group was characterised by ambiguous genitalia at birth with virilisation at puberty with subsequent male gender identity.

The median (range) age of the cohort was 33 (19-57) years, the median (range) age of first presentation was 13 (birth to 30) years and the median (range) age of gonadectomy was $14.5(0.6-35)$ years. In particular, gonadectomy was performed after the age of 13 years in 13 subjects of whom ten described virilisation at puberty, two were unclear about the experience of puberty and one 17-year old who had no sign of virilisation either in childhood or at puberty and was included because she had an absent uterus and her older sister had virilised at puberty. Subjects from South Asia were over represented in this group compared with average UK data reflecting the population mix of central London. Parental consanguinity was recorded in $6 / 23$ (26\%) subjects.

At the first clinic appointment, 14 women had previously acquired a clinical label of PAIS of whom four had normal sequence of the AR previously established, two were considered to have SRD5A2 deficiency based on low blood concentrations of dihydrotestosterone and one had the vanishing testis syndrome. Exact diagnostic criteria were not always available in referral letters and historic documents. History was taken to record gender assignment at birth and sex of rearing. Of the 14 women, eight were primary referrals as adults with no previous diagnosis.
The project was approved by the ethics committee of UCL Hospitals and informed consent was obtained from all subjects.

\section{Urinary steroid profile analysis}

Female and male subjects provided either a $24 \mathrm{~h}$ urine collection $(n=9)$ or a mid-morning random urine $(n=18)$. Analysis of samples from 12 controls previously established that there was no significant diurnal variation in the ratios of $5 \alpha$ - to $5 \beta$-reduced metabolites comparing daytime to night-time urine samples (data available on request). A $5 \mathrm{ml}$ aliquot of urine was used for analysis by gas chromatography and mass spectrometry (GC-MS) to provide a steroid profile as described previously (9). From the total ion current, chromatograms in the GC-MS data ratios of peak areas of A/Ae, $5 \alpha-\mathrm{THF} / \mathrm{THF}$ and $5 \alpha-\mathrm{THB} / \mathrm{THB}$ were used as indices of $5 \alpha$-reductase activity. Reference ranges established in this laboratory for $\mathrm{A} / \mathrm{Ae}$ and $5 \alpha$-THF/THF were $0.67-2.20$ and $0.42-1.1$ respectively in 26 adult males whereas in 31 females ranges were 0.42-1.08 and $0.17-0.95$ respectively. The data analyses for the ratio of $5 \alpha-\mathrm{THB} / \mathrm{THB}$ were performed retrospectively on archived MS data. Ratios were determined from the signals for specific ions at $\mathrm{m} / \mathrm{z} 564$ and 188. Insufficient data was available for $3 / 26$ subjects for this parameter. Reference ranges for $5 \alpha$-THB/THB were 0.9-4.0 for adult males. For the purposes of this study, it was considered that the male reference range was most appropriate to define abnormally low SRD5A2 activity. A fourth ratio, $11 \beta$-hydroxyandrosterone to $11 \beta$ hydroxyaetiocholanolone, proved unreliable as it was affected by co-elution of variable amounts of 17-hydroxypregnanolone with $11 \beta$-hydroxyandrosterone.

\section{SRD5A2 mutation screening}

DNA was extracted either from whole blood collected into EDTA or from saliva specimens. The SRD5A2 gene was analysed following amplification in three fragments containing exons 1, 2-4 and exon 5 respectively. Final reaction conditions for exons 1 and 5 contained $0.2 \mathrm{mM}$ dNTP, $1.5 \mathrm{mM} \mathrm{MgCl}_{2}$ and $500 \mathrm{nM}$ of each primer, 1 XGO taq buffer and 0.25 units Taq polymerase (GO Taq, Promega) in $25 \mu \mathrm{l}$ reaction volume. For exons $2-4$, the final concentration of reagents was $0.35 \mathrm{mM}$ dNTP, $1 \times$ buffer (Expand system 2, Roche Diagnostics), $320 \mathrm{nM}$ each primer and 0.1 unit Taq polymerase (Expand, Roche Diagnostics) in a final reaction volume of $25 \mu \mathrm{l}$. Following amplification, primers were removed using QIAquick PCR purification kit (Qiagen) and cycle sequencing performed using exon-specific primers. The products were sequenced on an ABI 310 genetic analyser.

Numbering of mutations was based on reference cDNA sequence NM_000348.3, with nucleotide +1 as the A of the ATG translation initiation codon. In silico analysis of missense changes was performed using SIFT 
(16; http://sift.jcvi.org/) and Polyphen-2 (17; http:// genetics.bwh.harvard.edu/pph2/) programmes. Potential splice site mutations were assessed using Human Splice Finder v 2.4.1(15; http://www.umd.be/HSF/).

\section{Results}

Sequencing of the SRD5A2 gene revealed pathological mutations in 10/23 (43\%) female subjects and in all four male patients (Table 1). Of these mutations, seven have been previously reported comprising six missense (p.Gln126Arg, p.Gly196Ser, p.Arg227X, p.His231Arg, p.Arg246Trp and p.Arg246Gln) (10-13) and one splice site mutation c.698+1G $>\mathrm{T}$ (14); four were novel mutations c.311G $>$ A (p.Gly104Gln), c.358A $>$ C (p.Thr120Pro), c.587G $>$ A (p.Gly196Asp) and a mutation in the splice acceptor site of intron 4, c.6991G $>$ A. The mutations c.586G $>$ A (p.Gly196Ser) and c.587G $>$ A (p.Gly196Asp) were found in the same patient and were confirmed as being on separate alleles by cloning. The c.699-G $>$ A occurs in the invariant region of the splice donor site and was predicted to affect splicing using Human Splicing Finder (15).

In the absence of expression studies, prediction of pathogenicity of the missense changes rely on the absence of the change in controls and in silico analysis of the effect of the changes on protein structure using SIFT (16) and Polyphen (17). Both SIFT and Polyphen predict that Gly196Asp is likely to be pathogenic with scores of $0.0(<0.05$ suggests pathogenicity) and $2.514(>2.0$ probably damaging) respectively; in addition, the variant was not found in 50 controls. A previously described mutation at the same position, Gly196Ser, is known to reduce the affinity of the enzyme for NADPH and reduces activity to $8.3 \%$ of normal (14). Thr120Pro was predicted to be possibly damaging by Polyphen (score 1.876), but not by SIFT (score 0.06). This change was not, however, found in the controls. Although this amino acid is not conserved throughout the species, an amino acid with some degree of hydrophobicity is preferred and proline does not share this property; in addition proline is a well-known helix breaker (18). The third change, Gln104, found in one male subject (Table 1; M3) is not predicted to have functional consequences by either SIFT (score 1.1) or Polyphen, although the Polyphen score of 0.849 is higher than that usually expected with a benign variant. This change occurs at a residue that is fully conserved throughout species and the substitution with a larger, more polar amino acid could potentially interfere with conformation. As this mutation occurs with a documented mutation (Arg246Trp) on the other allele and in a biochemically confirmed subject with intact gonads, it is likely to be pathogenic, although final proof would require expression studies. The change did not affect a restriction enzyme site and could, therefore, not be easily checked in controls.
In comparison to the normal male reference range, reduced ratios of $\mathrm{A} / \mathrm{Ae}$ metabolites $(<0.67)$ were found in $12 / 23(52 \%)$ subjects, $5 \alpha$-THF/THF metabolites $(<0.42)$ in $13 / 23(57 \%)$ and $5 \alpha-\mathrm{THB} / \mathrm{THB}(<0.90)$ in 10/22 (45\%) (Table 1 and Fig. 1). Figure 1 shows the mutation status according to urine steroid profile (USP) result, and it can be seen that the $\mathrm{A} / \mathrm{Ae}$ and $5 \alpha$-THB/THB ratios give better separation of mutationpositive subjects from the reference range compared with the $5 \alpha$-THF/THF ratio. Using the established lower limits of normal A/Ae ratio was $100 \%$ sensitive for the identification of mutation-positive cases with $83 \%$ specificity; $5 \alpha$-THF/THF ratio was $90 \%$ sensitive with $69 \%$ specificity; $5 \alpha$-THB/THB ratio was $100 \%$ sensitive with $83 \%$ specificity. By combining results for all three ratios, the sensitivity was $90 \%$ and specificity increased to $92 \%$ with only one individual negative for SRD5A2 mutation who had low ratios for all three pairs of metabolites.

\section{Discussion}

Clarification of the precise genetic basis for 46XY DSD is important for genetic counselling for each family. In this study, we have shown that a significant proportion (41\%) of 46XY DSD females have SRD5A2 deficiency and that this diagnosis should be considered for individuals labelled as PAIS, particularly, but not exclusively, those that virilise post-puberty. A similar prevalence of SRD5A2 mutations has been reported in a paediatric population of 46XY under-masculinised children (19), making this condition a more prominent component of the DSD population than previously considered.

Other disorders have been found in 46XY DSD cohorts of predominantly paediatric populations. From the Cambridge DSD database, AR mutations were found in $28 \%$ subjects with PAIS analysed by gene sequencing (20). The Dutch nationwide survey found 32/49 (65\%) of possible AIS subjects to have $A R$ gene mutations and $12(24 \%)$ with mutations in the HSD17B3 gene (2). An earlier analysis from this same group reported that $13 / 18$ cases previously thought to have AIS were ultimately found to have mutations in HSD17B3 (21). We now extend the understanding of 46XY DSD to estimate the proportion attributable to SRD5A2 deficiency. When considering the PAIS phenotype in all published cases, we estimate that a similar proportion of cases are accountable by AR, HSD17B3 and SRD5A2 gene mutations with $\sim 25 \%$ unaccounted for.

In our study, the largest cohort of adult 46XY DSD females to be screened biochemically and genetically, six of the ten women with SRD5A2 deficiency had gonadectomy after puberty. In addition, this group included some subjects with unusually late diagnoses. There are several factors that can account for late presentation. First, some of the subjects originating 


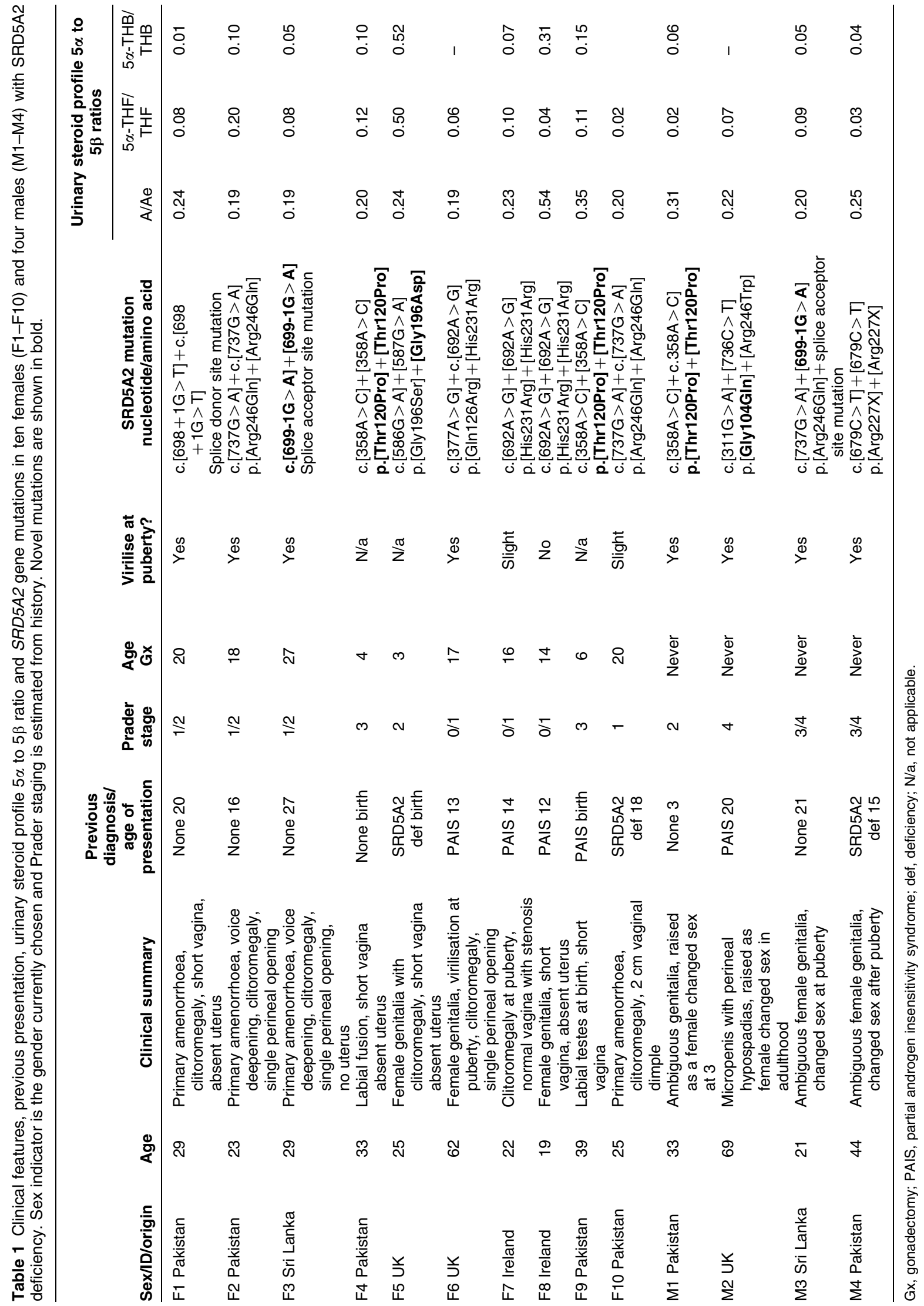



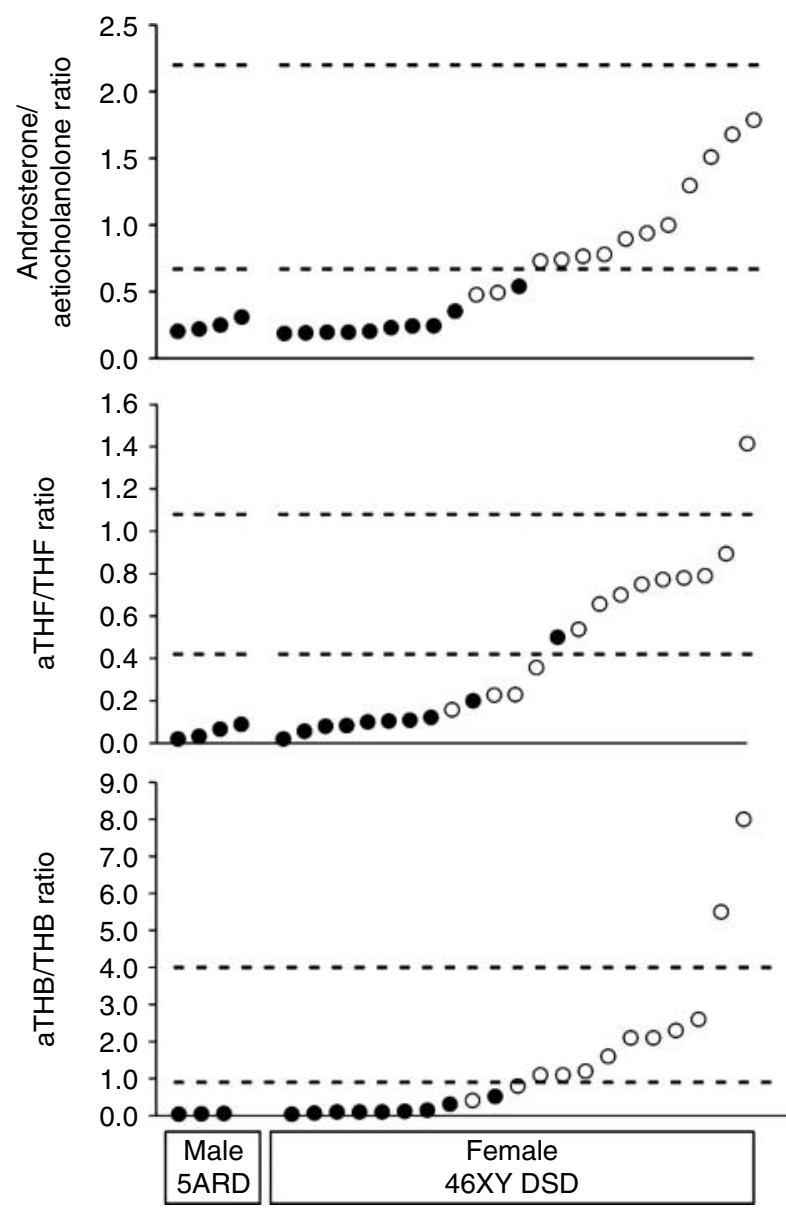

Figure 1 Urinary steroid profile ratios of $\mathrm{A} / \mathrm{Ae}, 5 \alpha-\mathrm{THF} / \mathrm{THF}$ and $5 \alpha-\mathrm{THB} / \mathrm{THB}$ ordered according to the ascending values for each ratio. SRD5A2 gene mutations are shown as positive in solid circle and negative in open circles. Dotted lines represent minimum and maximum male reference range. Four male subjects with SRD5A2 deficiency are shown at the left followed by females with 46XY DSD.

from South Asia as adults did not have access to specialist medical care. Secondly, if the original diagnostic work up was carried out in non-specialist units, the rate of missed or wrong diagnosis can be particularly high. In our sample, $28 \%$ of subjects referred to our DSD clinic with a diagnosis of PAIS (based on the phenotype and not genetically confirmed) turned out to have SRD5A2 deficiency. Finally, severe deficiency of activity of the SRD5A2 enzyme could result in late recognition if favouring a particularly female phenotype. In this regard, two females in our population with SRD5A2 mutations were sisters who grew up in a favourable social and medical context and were first investigated at puberty for primary amenorrhoea and mild virilisation (F7 and F8). The mutation in these individuals, p.His231Arg, alters testosterone binding (22) and has been described previously, in one case as a heterozygote (14) and in another homozygous for the change (23). The latter individuals presented and remained female but experienced virilisation at puberty, suggesting that this might be a severe mutation with a predominantly female phenotype. One of these sisters is important to note because on her own, she might have been classified as having CAIS and was not for her virilised sibling. This case raises the possibility that the female end of the SRD5A2 deficiency spectrum extends into the CAIS phenotype and this area is worthy of further exploration.

Of the four novel mutations we, one, Thr120Pro, was found in two unrelated subjects (F4 and F9 in Table 1) from Pakistan. The novel c.699-1G>A splice site mutation occurred in two unrelated subjects (F3 and M3) originating from Sri Lanka within the Tamil ethnic group.

USP has been used in the paediatric setting showing good agreement with SRD5A2 genetic testing (24). This report was interesting because of the inclusion of a heterozygote mother with a reduced A/Ae ratio of 0.39 , that is within our diagnostic range for SRD5A2 deficiency. Other studies also show overlap of USP results for carriers (25-28). Our series extends this experience in a more heterogeneous adult group in an attempt to map the area where USP and genetic results may be discrepant. The USP appears to be a rapid and reliable method to screen subjects with 46XY DSD for SRD5A2 deficiency rationalising genetic screening in a targeted, cost-efficient manner. Allowing for the fact that mutation-positive cases may exist with a higher A/Ae ratio than the highest value we have found (0.54), we would recommend applying mutation screening to all 46XY subjects with an A/Ae ratio of $<0.67$ - the lower limit of the normal male range. There are some differences in reference ranges between laboratories for normal subjects, patients and carriers, probably reflecting differences in rates of hydrolysis of conjugates during the analytical procedure. An international EQA scheme operated from our centre is seeking to find the cause of assay variations.

\section{Limitations and bias in this study}

The main outcomes of this study are affected by the ascertainment bias of the clinical service at our centre. The majority of subjects with 46XY DSD in our clinics are referred through a gynaecology pathway and the population served by our centre has a high degree of ethnic diversity. It was not possible to include samples matched for ethnicity in the control group to be certain that the novel gene alterations exist in each ethnic subgroup.

\section{Conclusions}

SRD5A2 deficiency is more prevalent than that expected in an adult 46XY female DSD population and this suggests that this diagnosis is often missed. USP is 
an effective preliminary diagnostic test for this disease, the A/Ae, $5 \alpha$-THB/THB ratios and $5 \alpha-\mathrm{THF} / \mathrm{THF}$ ratio are effective in discriminating the SRD5A2 mutationpositive subjects from normal and identifies those patients in whom sequencing of SRD5A2 gene will be beneficial for definitive diagnosis.

\section{Declaration of interest}

The authors declare that there is no conflict of interest that could be perceived as prejudicing the impartiality of the research reported.

\section{Funding}

This research did not receive any specific grant from any funding agency in the public, commercial or not-for-profit sector.

\section{References}

1 Hughes IA, Houk C, Ahmed SF \& Lee PA. Consensus statement on management of intersex disorders. Archives of Disease in Childhood 200691 554-563. (doi:10.1136/adc.2006.098319)

2 Boehmer AL, Brinkmann O, Bruggenwirth H, van Assendelft C, Otten BJ, Verleun-Mooijman MC, Niermeijer MF, Brunner HG, Rouwe CW, Waelkens JJ, Oostdijk W, Kleijer WJ, van der Kwast TH, de Vroede MA \& Drop SL. Genotype versus phenotype in families with androgen insensitivity syndrome. Journal of Clinical Endocrinology and Metabolism 200186 4151-4160. (doi:10. 1210/jc.86.9.4151)

3 Minto CL, Crouch NS, Conway GS \& Creighton SM. XY females: revisiting the diagnosis. British Journal of Obstetrics and Gynaecology 2005112 1407-1410. (doi:10.1111/j.1471-0528. 2005.00664.x)

4 Peterson RE, Imperato-McGinley J, Gautier T \& Shackleton C. Urinary steroid metabolites in subjects with male pseudohermaphroditism due to 5 alpha-reductase deficiency. Clinical Endocrinology 198523 43-53. (doi:10.1111/j.1365-2265.1985.tb00181.x)

5 Imperato-McGinley J, Peterson RE, Gautier T \& Sturla E. Male pseudohermaphroditism secondary to 5 alpha-reductase deficiency - a model for the role of androgens in both the development of the male phenotype and the evolution of a male gender identity. Journal of Steroid Biochemistry 197911 637-645. (doi:10.1016/ 0022-4731(79)90093-1)

6 Imperato-McGinley J \& Zhu YS. Androgens and male physiology the syndrome of 5alpha-reductase-2 deficiency. Molecular and Cellular Endocrinology 2002198 51-59. (doi:10.1016/S03037207(02)00368-4)

7 Mendonca BB, Domenice S, Arnhold IJ \& Costa EM. 46,XY disorders of sex development (DSD). Clinical Endocrinology 2009 70 173-187. (doi:10.1111/j.1365-2265.2007.02993.x-i1)

8 Berra M, Liao LM, Creighton SM \& Conway GS. Long-term health issues of women with XY karyotype. Maturitas 201065 172-178. (doi:10.1016/j.maturitas.2009.12.004)

9 Honour JW. Urinary steroid profile analysis. Clinica Chimica Acta 2001313 45-50. (doi:10.1016/S0009-8981(01)00648-9)

10 Silver RI \& Russell DW. 5alpha-reductase type 2 mutations are present in some boys with isolated hypospadias. Journal of Urology 1999162 1142-1145. (doi:10.1016/S0022-5347(01) 68102-3)

11 Fernandez-Cancio M, Rodo J, Andaluz P, Martinez de Osaba MJ, Rodriguez-Hierro F, Esteban C, Carrascosa A \& Audi L. Clinical, biochemical and morphologic diagnostic markers in an infant male pseudohermaphrodite patient with compound heterozygous mutations (G115D/R246W) in SRD5A2 gene. Hormone Research 200462 259-264. (doi:10.1159/000081893)
12 Hackel C, Oliveira LE, Ferraz LF, Tonini MM, Silva DN, Toralles MB, Stuchi-Perez EG \& Guerra-Junior G. New mutations, hotspots, and founder effects in Brazilian patients with steroid 5alpha-reductase deficiency type 2. Journal of Molecular Medicine 200583 569-576. (doi:10.1007/s00109-005-0651-7)

13 Sahu R, Boddula R, Sharma P, Bhatia V, Greaves R, Rao S, Desai M, Wakhlu A, Phadke S, Shukla M, Dabadghao P, Mehrotra RN \& Bhatia E. Genetic analysis of the SRD5A2 gene in Indian patients with 5alpha-reductase deficiency. Journal of Pediatric Endocrinology $\mathcal{E}$ Metabolism 200922 247-254. (doi:10.1515/JPEM.2009. 22.3.247)

14 Thigpen AE, Davis DL, Milatovich A, Mendonca BB, ImperatoMcGinley J, Griffin JE, Francke U, Wilson JD \& Russell DW. Molecular genetics of steroid 5 alpha-reductase 2 deficiency. Journal of Clinical Investigation 199290 799-809. (doi:10.1172/ JCI115954)

15 Desmet FO, Hamroun D, Lalande M, Collod-Beroud G, Claustres M \& Beroud C. Human Splicing Finder: an online bioinformatics tool to predict splicing signals. Nucleic Acids Research 200937 e67. (doi:10.1093/nar/gkp215)

16 Ng PC \& Henikoff S. SIFT: predicting amino acid changes that affect protein function. Nucleic Acids Research 200331 3812-3814. (doi:10.1093/nar/gkg509)

17 Adzhubei IA, Schmidt S, Peshkin L, Ramensky VE, Gerasimova A, Bork P, Kondrashov AS \& Sunyaev SR. A method and server for predicting damaging missense mutations. Nature Methods 20107 248-249. (doi:10.1038/nmeth0410-248)

18 Arnold K, Bordoli L, Kopp J \& Schwede T. The SWISS-MODEL workspace: a web-based environment for protein structure homology modelling. Bioinformatics 200622 195-201. (doi:10. 1093/bioinformatics/bti770)

19 Nicoletti A, Baldazzi L, Balsamo A, Barp L, Pirazzoli P, Gennari M, Radetti G, Cacciari E \& Cicognani A. SRD5A2 gene analysis in an Italian population of under-masculinized $46, \mathrm{XY}$ subjects. Clinical Endocrinology 200563 375-380. (doi:10.1111/j.1365-2265. 2005.02348.x)

20 Ahmed SF, Cheng A, Dovey L, Hawkins JR, Martin H, Rowland J, Shimura N, Tait AD \& Hughes IA. Phenotypic features, androgen receptor binding, and mutational analysis in 278 clinical cases reported as androgen insensitivity syndrome. Journal of Clinical Endocrinology and Metabolism 200085 658-665. (doi:10.1210/ jc.85.2.658)

21 Boehmer AL, Brinkmann AO, Sandkuijl LA, Halley DJ, Niermeijer MF, Andersson S, de Jong FH, Kayserili $\mathrm{H}$, de Vroede MA, Otten BJ, Rouwe CW, Mendonca BB, Rodrigues C, Bode HH, de Ruiter PE, Delemarre-van de Waal HA \& Drop SL. 17Beta-hydroxysteroid dehydrogenase-3 deficiency: diagnosis, phenotypic variability, population genetics, and worldwide distribution of ancient and de novo mutations. Journal of Clinical Endocrinology and Metabolism $1999 \mathbf{8 4}$ 4713-4721. (doi:10. $1210 /$ jc.84.12.4713)

22 Wigley WC, Prihoda JS, Mowszowicz I, Mendonca BB, New MI, Wilson JD \& Russell DW. Natural mutagenesis study of the human steroid 5 alpha-reductase 2 isozyme. Biochemistry 1994 33 1265-1270. (doi:10.1021/bi00171a029)

23 Boudon C, Lumbroso S, Lobaccaro JM, Szarras-Czapnik M, Romer TE, Garandeau P, Montoya P \& Sultan C. Molecular study of the 5 alpha-reductase type 2 gene in three European families with 5 alpha-reductase deficiency. Journal of Clinical Endocrinology and Metabolism 199580 2149-2153. (doi:10.1210/jc.80.7. 2149)

24 Chan AO, But BW, Lau GT, Lam AL, Ng KL, Lam YY, Lee CY \& Shek CC. Diagnosis of 5alpha-reductase 2 deficiency: a local experience. Hong Kong Medical Journal 200915 130-135.

25 Imperato-McGinley J, Peterson RE, Gautier T, Arthur A \& Shackleton C. Decreased urinary C19 and C21 steroid 5 alphametabolites in parents of male pseudohermaphrodites with 5 alpha-reductase deficiency: detection of carriers. Journal of Clinical Endocrinology and Metabolism 198560 553-558. (doi:10. 1210/jcem-60-3-553) 
26 Imperato-McGinley J, Miller M, Wilson JD, Peterson RE, Shackleton C \& Gajdusek DC. A cluster of male pseudohermaphrodites with 5 alpha-reductase deficiency in Papua New Guinea. Clinical Endocrinology 199134 293-298. (doi:10.1111/j.13652265.1991.tb03769.x)

27 Imperato-McGinley J, Shackleton C, Orlic S \& Stoner E. C19 and C21 5 beta/5 alpha metabolite ratios in subjects treated with the 5 alpha-reductase inhibitor finasteride: comparison of male pseudohermaphrodites with inherited 5 alpha-reductase deficiency. Journal of Endocrinology and Metabolism 199070 777-782. (doi:10.1210/jcem-70-3-777)
28 Can S, Zhu YS, Cai LQ, Ling Q, Katz MD, Akgun S, Shackleton CH \& Imperato-McGinley J. The identification of 5 alpha-reductase-2 and 17 beta-hydroxysteroid dehydrogenase-3 gene defects in male pseudohermaphrodites from a Turkish kindred. Journal of Endocrinology and Metabolism $1998 \mathbf{8 3}$ 560-569. (doi:10.1210/ jc.83.2.560)

Received 10 March 2011

Accepted 14 March 2011 